Journal of

Ecology 1994,

82, 217-226

\title{
The influences of tree biology and fire in the spatial structure of the West African savannah
}

\author{
MICHAEL E. HOCHBERG, JEAN CLAUDE MENAUT and \\ JACQUES GIGNOUX \\ Ecole Normale Supérieure, Laboratoire d'Ecologie, CNRS - URA 258, 46, rue d'Ulm, 75230 Paris Cedex 05, \\ France
}

\begin{abstract}
Summary
1 Using a spatially explicit cellular automaton model we explore the effects of tree demography, fire-induced mortality, and seed dispersal on the spatial spread of a single tree species in a humid savanna at Lamto in West Africa.

2 The model system is described by six parameters and consists of a grass-surrounded square grid of connecting cells, each being either inhabited by grass alone or by grass and an individual tree. In the baseline numerical simulations the tree can only recruit seedlings in immediately adjacent cells. These seedlings may perish from annual grass fires in their first year of life if they are not protected from the advancement of the fire by neighbouring reproductively mature trees.

3 Based on preliminary parameter estimates from data collected at field sites at Lamto, we predict that fire slows, but does not stop, the spread of the tree. In the absence of fire the doubling rate of the tree population is about 6 years, whereas we predict that yearly fires prolong this to at least 30 years.

4 The temporal dynamics of the tree population are fairly smooth and predictable as long as there are more than $c .100$ cells in the system. As the number of cells is decreased below $c .100$ the trajectories become increasingly variable from year to year.

5 Mortalities from fire act in an inverse spatially density-dependent fashion, enhancing tree aggregation. The role of fire in enhancing tree aggregation is supported by additional simulations in which dispersal of seeds to non-adjacent cells can occur. When a small amount of dispersal is possible the rate of tree population growth is greatly accelerated as compared to when no such dispersal occurs.

6 We present several hypotheses to explain why the savanna at Lamto is not treedominated as would be predicted by the model, discuss how seed dispersal and fire influence tree dynamics, and make predictions for future testing.
\end{abstract}

Keywords: cellular automaton, dispersal, fire, population dynamics, savannah, treegrass equilibrium

Journal of Ecology (1994) 82, 217-226

\section{Introduction}

The patchy occurrence of trees in what is otherwise an immense grassland characterizes the large-scale vegetative structure of the humid West African savannas (Menaut 1983). At a 2500-ha site at the Lamto Reserve $\left(5^{\circ} 02^{\prime} \mathrm{W}, 6^{\circ} 13^{\prime} \mathrm{N}\right.$; Ivory Coast) burning occurs once yearly in the dry season as a management practice to decrease the grass cover for better hunting, to reduce the risk of accidental fires, and to initiate fire burns most or all of the above ground biomass of grass species, their large underground root systems enable them to survive even the most intense fires and rapidly to establish new shoots before the onset of the rainy season. In contrast to grasses, individuals of woody species which are less than $c .2 \mathrm{~m}$ in height may either succumb to fire or have their growth retarded. Mature trees and shrubs beyond c. $2 \mathrm{~m}$ are more fire resistant and only experience die-back (Menaut \& César 1979; Gillon 1983).

Amongst the determinants controlling tree-grass 
Tree biology, fire and spatial population dynamics coexistence (i.e. soil moisture, soil nutrients, herbivory and fire), only herbivory and fire would appear to have sufficient variation in regime and intensity to induce rapid changes in vegetation structure at the patch scale (Frost et al. 1986). The role of herbivory, alone or in interaction with fire, has been given considerable attention in Eastern and Southern Africa (Norton-Griffiths 1979; Pellew 1983; Trollope 1984), but cannot be an important factor at Lamto where grazing and browsing animals (domestic or wild) are absent. It is generally agreed that fire, per se, favours the development and maintenance of a predominantly grassland vegetation, since young tree individuals are likely to perish from fire when surrounded by a sufficiently large fuel-load of dry grass. Tree-dominated patches are, however, maintained since reproductively mature, fire-resistant woody individuals depress the growth of grass and hence reduce the detrimental effects of fire to younger tree individuals (Trollope 1984; Frost \& Robertson 1987 and references in both).

Very few simulation models have addressed the balance between grasses and trees in savannahs. Those that have, focused on soil water availability and differential absorption by grass and tree systems either alone (Eagleson 1988) or in interaction with herbivory (Walker et al. 1981), and few studies have incorporated fire. Norton-Griffiths (1979) modelled the response of size-structure of tree populations to fire and herbivory in East African savannahs, but lacked data for the estimation of several important parameters, such as natural mortality in juvenile trees, and seedling establishment and competition with grasses. These models only simulated tree density and did not account for the patchiness of the vegetation.

In the Lamto savannah, tree distributions are highly aggregated irrespective of soil conditions, and the spread of fire depends on vegetation patterning (Menaut et al. 1990). In the present work, we hypothesize that both the tree-grass balance and vegetation patchiness are determined by interactions between plant biological attributes (e.g. tree demography, seed dispersal) and fire. We develop a simple, spatially explicit, cellular automaton simulation model to explore the spatial aspects of tree population dynamics and the major mechanisms which may act to maintain a tree-grass equilibrium. We propose several testable scenarios of the savannah tree dynamics at Lamto.

\section{The model}

In principle, the model developed here could apply to the movements of the savannah-forest boundary. However, studying the mechanisms that underlie the encroachment of the rain forest on the savannah would require a different model structure and parameter estimates from those presented here. Thus, we only consider variations in savannah tree density and spatial distribution, although these could appear, in the long term and under certain circumstances, as the first stages of rain forest succession into the savannah.

\section{BASIC FRAMEWORK}

The various modelling approaches to plant community ecology have recently been reviewed by Czaran \& Bartha (1992). We use a minimally complicated algorithm so as to highlight the basic processes acting to determine spatial patterning in a single tree population. Our approach corresponds closely to the category of 'cellular automaton' models, where the habitat is broken-up into a grid of spatially distinct, interacting 'cells'. These cells can be either uninhabited or inhabited by a single dynamic entity, such as an individual plant or a group of plants.

We take a reductionist approach to modelling the system by considering only a single tree population. This is done to highlight how demography may influence tree population dynamics and to make predictions about the influence of fundamental processes on the tree population. These predictions can then be tested empirically and compared to future theoretical studies on multi-species communities and grass population dynamics.

The system is modelled as a $n \times n$ grid of square cells, the whole grid being surrounded by grassland. The equations governing the changes in cell occupation by trees are iterated once per calendar year, and at the beginning of a given iteration each cell can be in one of three states with respect to tree occupation: (i) unoccupied, (ii) occupied by reproductively immature trees, or (iii) occupied by mature trees. Demographic events can occur either purely within a cell (i.e. nonfire induced mortality), or in interaction with the eight immediately adjacent cells (i.e. mortality from fire, recruitment), or at longer distances (i.e. recruitment of dispersed seeds). The size of a given cell is $1 \mathrm{~m} \times 1 \mathrm{~m}$, which is approximately that permitting the growth of, at most, a single maximally reproductive individual ( $\mathrm{P}$. Mordelet, pers. comm.). Intraspecific competition is not explicitly considered in the model; when cells are occupied by more than one reproductively mature individual, the largest is assumed to rapidly displace its competitors (Antonovics \& Fowler 1985). We assume that treetree competition between cells is of the 'pre-emptive' type (sensu Schoener 1983), such that the first individual arriving in a cell cannot be directly displaced by another. What little is known about the dynamics of grasses at Lamto is that interspecific competition is highly asymmetrical in favour of woody species. In our model, interspecific effects occur via fire, such that the (constant) grass population has a negative impact on tree seedlings. Thus, the absence of trees imply the presence of (fire conducting) grasses. 
DESCRIPTION OF PROCESSES AND

PARAMETERS

The basic numerical algorithm functions by first apportioning mature trees between cells. At the beginning of year 1 , there is a probability Initial that a given cell will contain a newly mature tree of age RepAge. After this initial grid of mature trees is established, the model is iterated once per year until the end of the simulation. Within a given year a number of events may occur:

We take a first step towards modelling the effects of fire by considering only mortalities in young seedlings. Fire is assumed to burn once, at the beginning of the year, and over the whole of the savannah. At the beginning of any given year $t$, seedlings recruited in year $t-1$ are susceptible to fire-induced mortality with probability Burn. Burn is a function of the number of mature trees surrounding the seedling, such that

Burn $=1-S^{1-N_{\mathrm{p}} / B_{\mathrm{T}}}$

where $N_{\mathrm{p}}$ is the number of mature ('protecting') trees in cells surrounding the fire-prone plant $\left(0 \leqslant N_{\mathrm{p}} \leqslant\right.$ 8 ), $S$ is the survival of the plant from fire when $N_{\mathrm{p}}=0$, and $B_{\mathrm{T}}$ is the number of protecting trees at or above which the juvenile always survives fire. If $B_{\mathrm{T}}>8$, then, even if all eight cells surrounding a given juvenile are occupied by mature trees, there is always a risk of it perishing from fire. If a seedling dies from fire, then the cell it occupied becomes open to new recruitment in year $t+1$.

In any given empty cell that is adjacent to a mature tree there is a probability Colonize that a seed from that tree germinates and goes on to survive at least Rep Age years in the absence of fire. If an adjacent cell is already occupied by a seedling or a mature tree then recruitment cannot occur in that cell. (We assume that seeds germinate immediately upon falling to the ground). Colonize is given by

Colonize $=(1-\gamma)$ Recruit,

where $\gamma$ is the probability that this seed is dispersed and $1-\gamma$ is therefore the fraction of seeds available for recruitment in cells adjacent to the mother tree, and Recruit is the (constant) per cell recruitment rate. Recruitment rate as used here refers to the probability that a reproductively mature tree will produce a seedling in an adjacent empty cell and that that seedling will go on to survive at least to the age of reproductive maturity.

Alternatively, seeds can be dispersed by mechanisms other than those which typically result in recruitment in neighbouring cells such that Disperse, the probability of recruitment in any unoccupied cell (once local recruitment via Colonize has occurred), is a function of mature tree density $N_{\mathrm{m}}$,

Disperse $=(1-Q)^{N_{\mathrm{m}}}$,

where $Q$ is the probability that a given cell is not potentially colonized by a seed from any given mature tree $\left[Q=1-\left(\gamma\right.\right.$ Recruit $\left.\left./ n^{2}\right)\right]$. Note that a particular mother tree is not specified in Disperse, implying that a given mature tree can produce more than one dispersed colonising seed per year.

Mortalities in mature trees occur at the end of any given year with a constant probability DieOld that a mature tree dies (from factors acting independent of density). Otherwise, the mature tree ages one year.

Finally, if a juvenile tree survives RepAge years, then it becomes an adult at age RepAge +1 .

\section{BASELINE ESTIMATES OF PARAMETER CONSTANTS}

There is little quantitative information that can be used accurately to estimate the model parameters. To make first approximations, we employ field studies, not originally conceived for the purpose of parameter estimation. We stress that further experiments are needed to increase the precision of the estimates. One of the objectives of the sensitivity analysis (see below) is to explore how errors in parameter estimation can affect the model's behaviour.

Four species account for c. $90 \%$ of the trees at Lamto. They are Bridelia ferruginea Benth., Crossopteryx febrifuga Benth., Cussonia barteri Seeman, and Piliostigma thoningii Milne-Redhead (Menaut and César 1979). What information there is on the population biology of these species shows that (i) $B$. ferruginea, $C$. febrifuga and $P$. thoningii have the same types of growth curve (Gignoux 1988), (ii) B. ferruginea, $C$. barteri and $P$. thoningii have highly aggregated spatial patterns, whereas $C$. febrifuga is almost random (Menaut \& César 1979; Guiblin 1992), and (iii) tree aggregations are multi-specific and with no significant association between species (Guiblin 1992).

Given the coarse similarities between these species, we do not distinguish between them in making most of the estimates. The parameters are assigned the following baseline values (Table 1):

$n$. We take $n=50$, corresponding to a total system area of 0.25 ha.

RepAge. What little information there is on the age of reproductive maturity of the four dominant species suggests a value on the order of 5-10 years, although substantial variation is likely to exist within a given population. We employ the value of 5 years as a baseline estimate, meaning that a tree begins to reproduce in its sixth year of life.

DieOld. The probability that a mature tree dies in a given year is estimated from year to year records of individuals greater than $2 \mathrm{~m}$ in height (trees $>2 \mathrm{~m}$ are assumed to be mature) of the four dominant tree species from two unburned 0.25-ha sites (Gignoux 1988). This gives an estimate of DieOld $=0.015$, indi- 
Tree biology, fire and spatial population dynamics

Table 1 Baseline values for model parameters

\begin{tabular}{lll}
\hline Process or parameter & Symbol & Value \\
\hline Number of cells in system & $n^{2}$ & 2500 \\
Initial probability of occupation by mature tree & Initial & 0.1 \\
Age of tree at first reproduction & RepAge & 5 years \\
Probability of mortality of mature trees & DieOld & 0.015 \\
Fraction of potential seedling recruitment dispersed & $\gamma$ & 0 \\
Recruitment probability for adjacent cell & Recruit & 0.04 \\
Survival of immature trees after fire & $S$ & 0.141 \\
Number of encircling mature trees at or beyond which fire mortality is $0 \%$ & $B_{\mathrm{T}}$ & 8 \\
\hline
\end{tabular}

cating a $50 \%$ chance that a newly mature tree will survive 46 years.

$\gamma$. We have no data on spatial aspects of recruitment, and therefore initially assume that all recruitment occurs adjacent to mother trees $(\gamma=0$ and Disperse $=0$ ).

Recruit. We have no direct estimate of the probability that a mature tree will give rise to mature progeny in adjacent cells. We therefore estimate this parameter indirectly by noting that at a 0.25 -ha site protected from fire from 1967 onwards, numbers of trees of all four species greater than $2 \mathrm{~m}$ in height increased by $79 \%$ between 1970 and 1975 (from 132 to 236 trees, Menaut 1977). Note that this estimate should be dependent on tree density and age-structure, and the species composition of the community. We iterated the model in the absence of fire starting with 132 randomly distributed mature trees and, employing the baseline values for the other parameters, adjusted Recruit until the tree population grew by $c .80 \%$ over a 5 year period. This resulted in Recruit $=0.04$.

$S$. The probability of a seedling (1 year old or less) surviving from fire is estimated from data collected on Bridelia ferruginea from four 0.25-ha sites. In 1991 a total of 239 out of 302 new seedlings (79.1\%) and 5 out of $53(9.4 \%)$ trees less than $2 \mathrm{~m}$ tall perished from fire. To keep the model as simple as possible we group these mortalities into a single event occurring in the first year following recruitment, giving $85.9 \%$ mortality, or $S=0.141$. Simulations of fire-induced mortalities distributed over each of the first 5 years of a tree's life did not differ appreciably from the simplified model.

$B_{\mathrm{T}}$. We are not able to estimate $B_{\mathrm{T}}$ from data or observations, and assume that when the seedling is completely surrounded by trees it is fully protected from burning (i.e. $B_{\mathrm{T}}=8$ ).

\section{Results}

\section{BASIC REPRODUCTIVE RATE AND DOUBLING TIME}

An index of central importance in characterising tree demography is the basic reproductive rate, $R_{0}$. $R_{0}$ is the number of new seedlings produced from a single new seedling in the system (i.e. in the absence of initial competitors) over the life-time of the latter. In the context of our study, it is a contributing measure of the colonization potential of unoccupied grasslands, and the maximum rate of spread of the tree population through the grassland once established. When $R_{0}<1$ the tree population does not persist indefinitely.

Based on 1000 simulations, we estimate $R_{0}=3.17$ $(\mathrm{SD}=10.2)$. The large standard deviation is indicative of the fact that in $85.7 \%$ of the simulations, the seedling perished from fire and, in simulations where it survived, produced anywhere from 1 to 77 offspring during its mature life (Fig. la). Estimating $R_{0}$ from
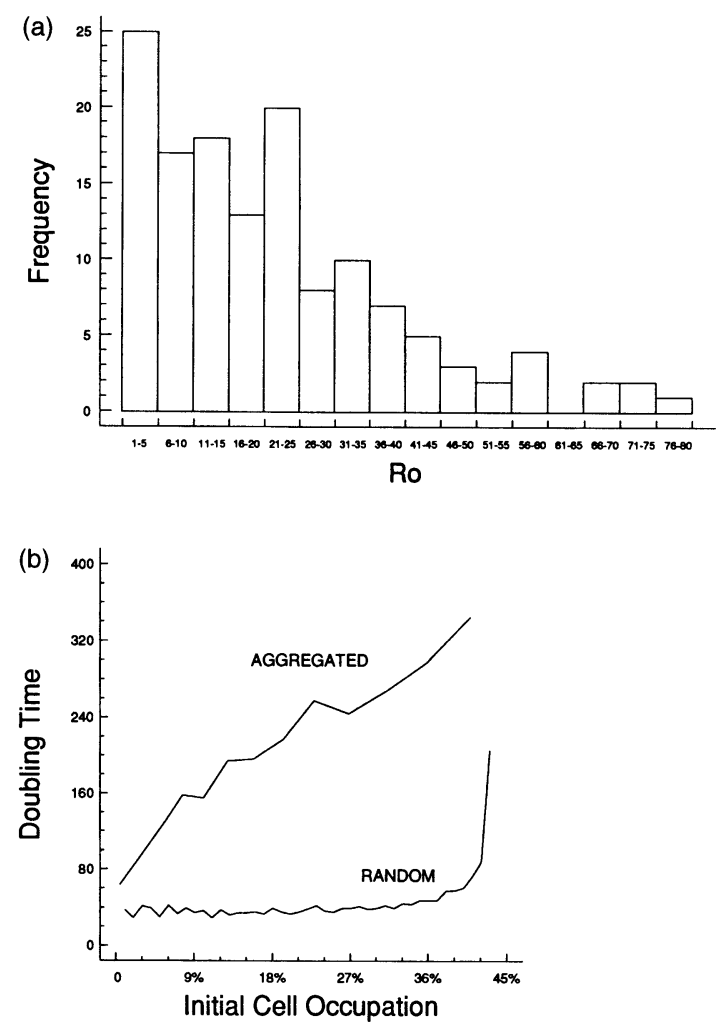

Fig. 1 (a) Frequency distribution of the 143 out of 1000 simulations resulting in basic reproductive rates of the tree population greater than zero. (b) Effect of initial cell occupancy by mature trees and initial mature tree distribution (random, or aggregated in the centre of the grid) on the doubling time of the mature tree population. Baseline parameter values are given in Table 1 . 
221

M.E. Hochberg,

J.C. Menaut \&

J. Gignoux field studies is therefore more efficiently done by shifting the reference point of the calculation, and counting the number of newly mature trees produced by an initial, newly mature tree.

We predict that, in the presence of yearly fires, the doubling time of an initially randomly dispersed tree population is c. 30-40 years (Fig. 1b). This estimation holds true until approximately $40 \%$ of the system is initially occupied by trees, beyond which (due to limits in the number of cells in the system) the doubling time rapidly approaches infinity. When mature trees are initially aggregated in the centre of the system, the doubling time is substantially increased, there being a roughly linear relationship between it and initial cell occupancy by mature trees at occupancy values up to about $40 \%$ (Fig. 1b).

\section{DYNAMICS}

Since our model is based on transition probabilities, the trajectories from one simulation to another invariably differ for any given set of initial conditions and parameter values. In general, these differences were very minor, and we present single, arbitrarily chosen, examples to express the typical trajectories observed. We note cases where simulations were highly variable from one to another.

In accordance with the doubling time of $30-40$ years, we found that the tree population reaches an equilibrium of $c .90 \%$ cell occupancy by mature trees in 1200 years following the introduction of a single mature tree into the system (Fig. 2a). It can be shown that an analytical approximation of the equilibrium $N^{*}$, based solely on the survival of mature trees, is

$N^{*} \approx 1-(1-\text { DieOld })^{\text {RepAge }}$,

resulting in $N^{*}=0.927$ for the baseline parameters. Equation 4 becomes increasingly accurate as

$N_{\mathrm{T}} \rightarrow 0$, DieOld $\rightarrow 0$, and RèpAge $\rightarrow 0$.

The trajectory of the mean age of mature trees is somewhat oscillatory for the first 500-1000 years, until the population reaches its equilibrium, after which the mean age equilibrates to approximately 70 years (i.e. $\approx 1$ / DieOld) (Fig. 2b). Note that this differs from the median age of the trees, which is predicted to be 51 years (cf. estimation of $\cdot \mathrm{DieO}$ (d).

To investigate the level of tree clumping, we employ two indices that calculate the average number of 'unique couplings' per mature tree (number of trees adjacent to one another, with a given coupling counted only once). For a saturated system of $n^{2}$ mature trees, there are on average 4 couplings per tree as $n \rightarrow \infty$. (For $n=50$ the maximum average number of couplings is $c$. 3.9.) The index $C$ is the number of couplings per mature tree, or

$C=\frac{X}{\text { Trees }}$,
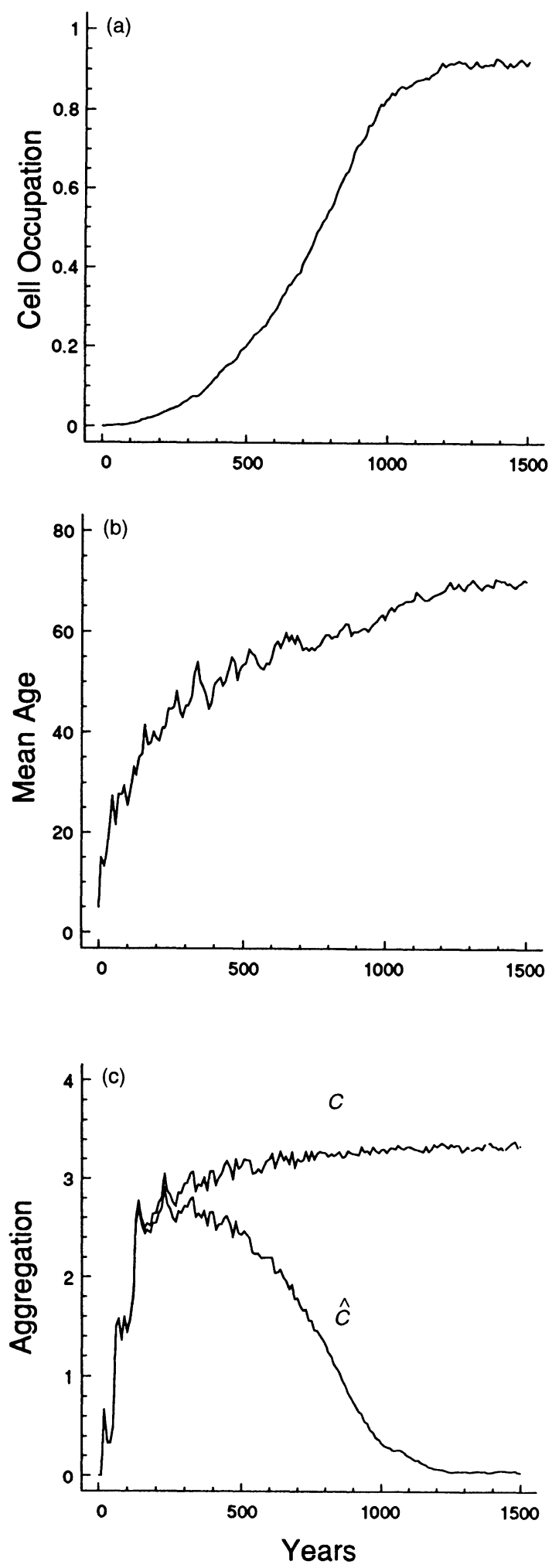

Fig. 2 Example of model dynamics using parameter values presented in Table 1. (a) Fraction of cells occupied by reproductively mature trees. (b) Mean age in years of mature trees in system. (c) Aggregation of mature trees according to indices $C$ and $\hat{C}$. The simulation began with a single mature tree in cell 25,25 . See text for definitions of aggregation indices. 
Tree biology, fire and spatial population dynamics where $X$ is the total number of (adjacent) tree couplings, and Trees is the total number of occupied cells.

$C$ increases with the population of mature trees, reaching and stabilising at a maximum value of about 2.7 mature neighbours per mature tree about 150 years after the introduction of a single mature tree in the system (Fig. 2c). $C$ does not reach the theoretical maximum of 3.9 due to the presence of empty cells and of cells containing juvenile trees.

The index $\hat{C}$ discounts $C$ by the expected number of couplings if the trees were distributed at random,

$\hat{C}=C-f \frac{\text { Trees }-1}{n^{2}-1}$,

where $f$ is the average expected maximum number of couplings per cell, or

$f=\left[4(n-2)^{2}+10(n-2)+6\right] / n^{2}$

such that $f \rightarrow 4$ as $n \rightarrow \infty$, and in our $50 \times 50$ system (for example) $f=3.9$.

The trajectories of $\hat{C}$ and $C$ are the same for about 500 years, the former descending thereafter towards 0 as the system fills with mature trees and the distribution approaches randomness. The highest levels of clumping (above that expected by chance) therefore last for about $300-400$ years following initial colonization.

Figure 3 shows a typical example of the spatial dynamics of the system for the baseline parameter values and initial conditions presented in Table 1. Aggregations of mature trees form around those mature trees initially in the system (a,b), and gradually. coalesce (c), the tree population continuing thereafter to spread to the edges of the system (d). It can further be seen from the example in Fig. 3 that relatively few of the juvenile trees present in any given year will survive to maturity. This is, to a considerable extent, due to fire-induced mortalities.

\section{SENSITIVITY}

The aim of the sensitivity analysis is to evaluate how changes in initial conditions and parameter values affect the dynamics of the system. Here, we focus on the indices of tree population level $\left(N_{\mathrm{m}} / n^{2}\right)$ and clumping $(\hat{C})$ for several of the more revealing parameters and processes.

As expected, increasing the initial tree population results in the more rapid attainment of the equilibrium situation (Fig. 4a). The initial tree population can have an important impact on tree clumping, simply because the system is more homogeneous from the start; aggregation attains greater levels if initial numbers of trees are small and patches are allowed to form (Fig. 4b).

Tree population growth is initially faster if the initial distribution of trees is more dispersed (Fig. 4c). This is somewhat counter-intuitive since juvenile trees are more protected when near large aggregations of trees. However, this protection effect is outweighed by the much higher level of competition for recruitment sites in aggregated systems. Due to the probabilistic nature of the system, an initially highly aggregated patch of trees becomes increasingly tattered at the edges with time, thus decreasing $\hat{C}$ (Fig. 4d).

The smaller the system size, the more prone it is to both temporal fluctuations and stochastic extinctions of trees, and the more idiosyncratic are the simulations. Beyond a system of approximately 100 cells $(n=10)$ the population dynamics are highly predictable (Fig. 4e,f).

What happens if our estimate of $B_{\mathrm{T}}$ is in error? Fig. 5a,b shows that for small changes in $B_{\mathrm{T}}$ this matters relatively little; decreasing $B_{\mathrm{T}}$ accelerates the rate of population growth (because fewer mature trees are needed to offer protection to the seedlings) and the associated spatial clumping peaks quickly at low levels. As $B_{\mathrm{T}}$ increases, aggregation peaks higher and later (Fig. 5b) up to $B_{\mathrm{T}}=4$, after which the maximum falls although the timing of the peak remains constant (60-70 years from the start of the simulation).

If we allow some seedlings to be dispersed into non-adjacent cells we see that tree population growth accelerates very rapidly, such that when $0.4 \%$ of potential seedlings are so dispersed, it takes less than 80 years for near-complete occupation of the system from an initial level of $10 \%$ (Fig. 5c). We see that even very small increases in dispersal lead to the rapid attainment of spatial homogeneity and smaller aggregation peaks (Fig. 5d) suggesting that dispersal diminishes spatial clumping.

\section{FIRE INDUCED EQUILIBRIUM?}

Numerical simulations (not presented here) show that fire does not change the equilibrium level of trees, unless the value of $S$ is less than about 0.02 , or the mortality of unprotected seedlings is greater than $98 \%$, in which case the tree population always eventually goes extinct (corresponding to $R_{0}<1$ ). This threshold value of $S$ would increase if our estimate of $B_{\mathrm{T}}$ were too high.

Furthermore, if $R_{0}<1$ is indeed the only condition preventing the eventual dominance of trees in the savannah, then our estimation of $R_{0}=3.17$ suggests that trees will eventually go extinct if the yearly per cell recruitment drops below c. $1.26 \%$ (i.e. Recruit $<0.04 / 3.17=0.0126$ ). Numerical simulations give a value of $c .0 .012$, confirming the accuracy of this estimate based on $R_{0}$.

\section{Discussion}

Given that fire is insufficient to stop the near-complete domination by trees of the West African savannah, how can we explain areas inhabited by grasses alone? 
223

M.E. Hochberg,

J.C. Menaut \&

J. Gignoux (a)

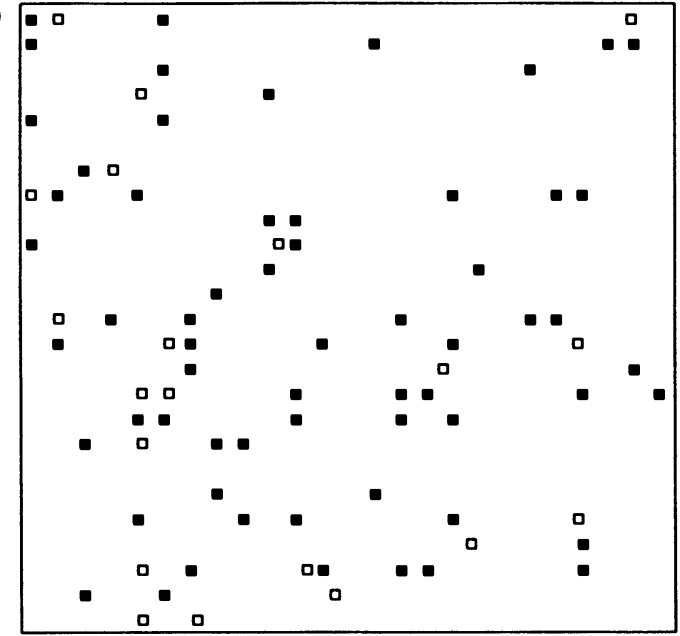

(b)

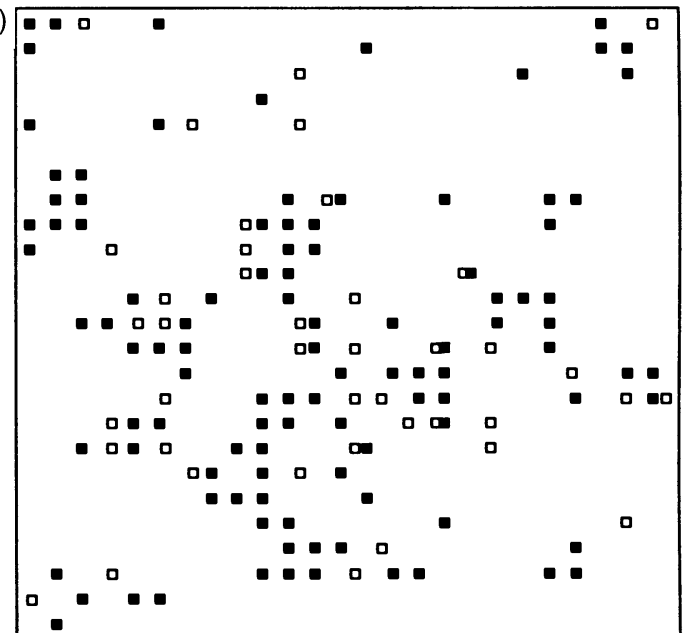

(c)

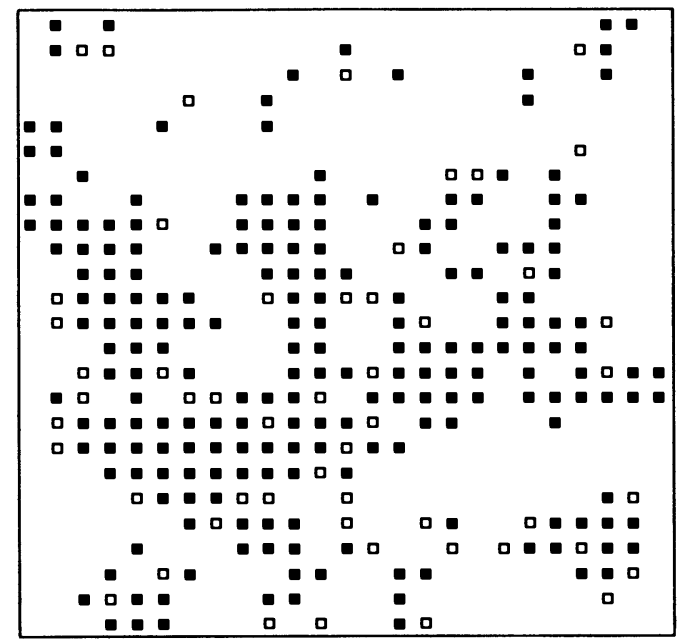

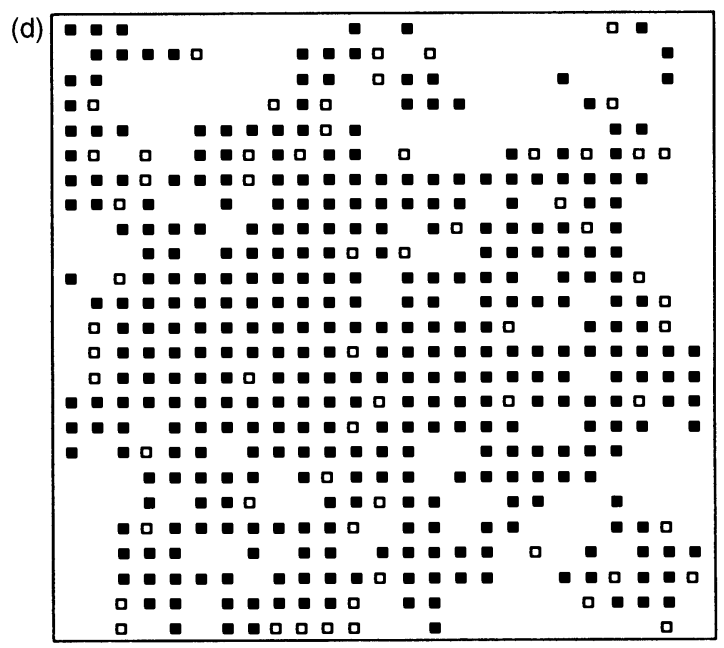

Fig. 3 Development of the spatial distributions of mature (solid squares) and juvenile (open squares) trees and corresponding mean age of mature trees, fraction of cells occupied by mature trees, and aggregation indices $C$ and $\hat{C}$. Parameter values are from Table 1, except for $n=25$. See text for definitions of aggregation indices.

\begin{tabular}{|c|c|c|c|c|}
\hline Year of simulation & Mean age(years) & Cell occupation $(\%)$ & $C$ & $\hat{C}$ \\
\hline (a) Year 1 & 5.0 & 10.2 & 0.39 & 0.011 \\
\hline (b) Year 20 & 18.3 & 23.5 & 1.14 & 0.532 \\
\hline (c) Year 50 & 28.0 & 41.0 & 2.15 & 0.905 \\
\hline (d) Year 100 & 38.3 & 65.8 & 2.76 & 0.628 \\
\hline
\end{tabular}

One possibility is that the basic reproductive rate of trees is less than unity in certain areas and/or over certain periods, permitting the persistence of grasses only. A mechanism which could give rise to this is insufficient physical or nutritive conditions for tree growth and reproduction. Our results show that tree dynamics in patches below about 100 cells in size are less predictable and more prone to extinction than are larger areas (e.g. Fig. 4e,f). Systems composed of many small, internally oscillatory, tree patches are indicative of seed dispersal and/or seed dormancy as mechanisms responsible for the persistence of the whole tree population.

The occurrence of grasses over large areas could also be explained by density- or age-dependent reductions in the competitive ability, reproductive output or survival of trees that are sufficient to offset inverse density dependent mortalities due to fire. Examples include the action of fire in older stands (Sanford et al. 1982), competition for limiting nutrients (Frost et al. 1986), or the impact of herbivores and diseases (Norton-Griffiths 1979). In previous modelling studies, Prado (1988) and Menaut et al. (1990) found that, although fire did not stop the eventual domination of the savannah by tree species, very strong competitive interactions could do so. Below, we discuss briefly the roles of seed dispersal and fire in structuring our model tree population and 
224

Tree biology, fire and spatial population dynamics
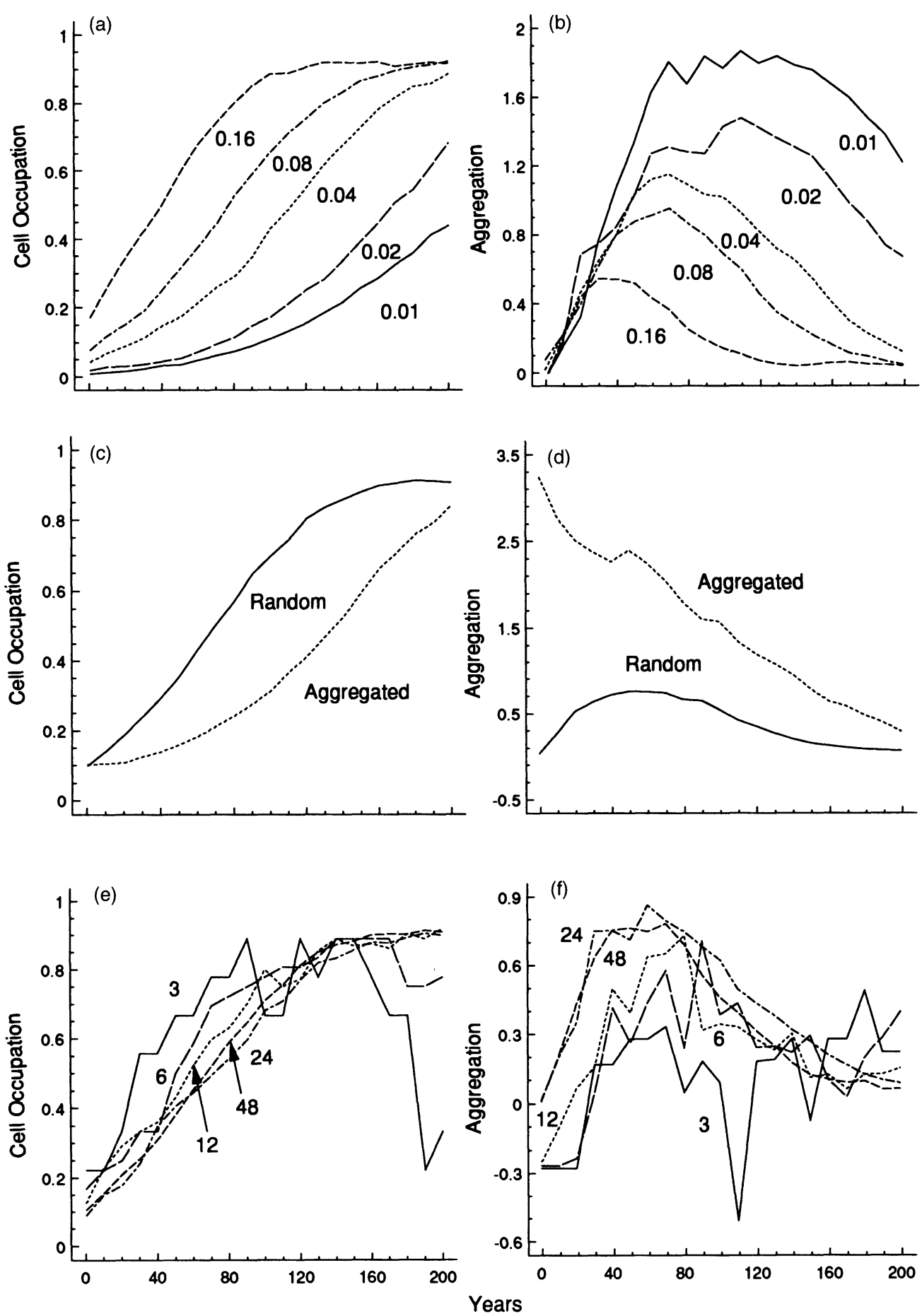

Fig. 4 Sensitivity of temporal changes in the fraction of cells occupied by mature trees $\left(N_{\mathrm{m}} / n^{2}\right)$ and the aggregation index to parameter changes and initial conditions. (a) and (b) Effect of initial fraction of cells occupied by mature trees (Initial). (c) and (d) Effect of initial distribution of mature trees (for aggregated distribution, all trees are initially distributed in a $16 \times 16$ cell block in the centre of the grid). (e) and (f) Effect of system size (value of $n$ ). Unless otherwise specified Initial $=0.1$ and trees are randomly distributed. See text for further explanations of parameters and indices.

present several testable predictions based on the results.

\section{THE ROLE OF SEED DISPERSAL IN TREE} DYNAMICS

We found that spatial spread of trees is more rapid in systems where seeds are dispersed, as opposed to systems in which no dispersal occurs. This is, at first sight, an unexpected result because seed dispersal in our model entails a cost to potential local recruitment and dispersed seedlings have a greater chance of burning than locally recruited ones. However, when tree density is sufficiently low, dispersed seedlings have an advantage over nondispersed ones in that the former experience much lower levels of pre-emptive compe- 

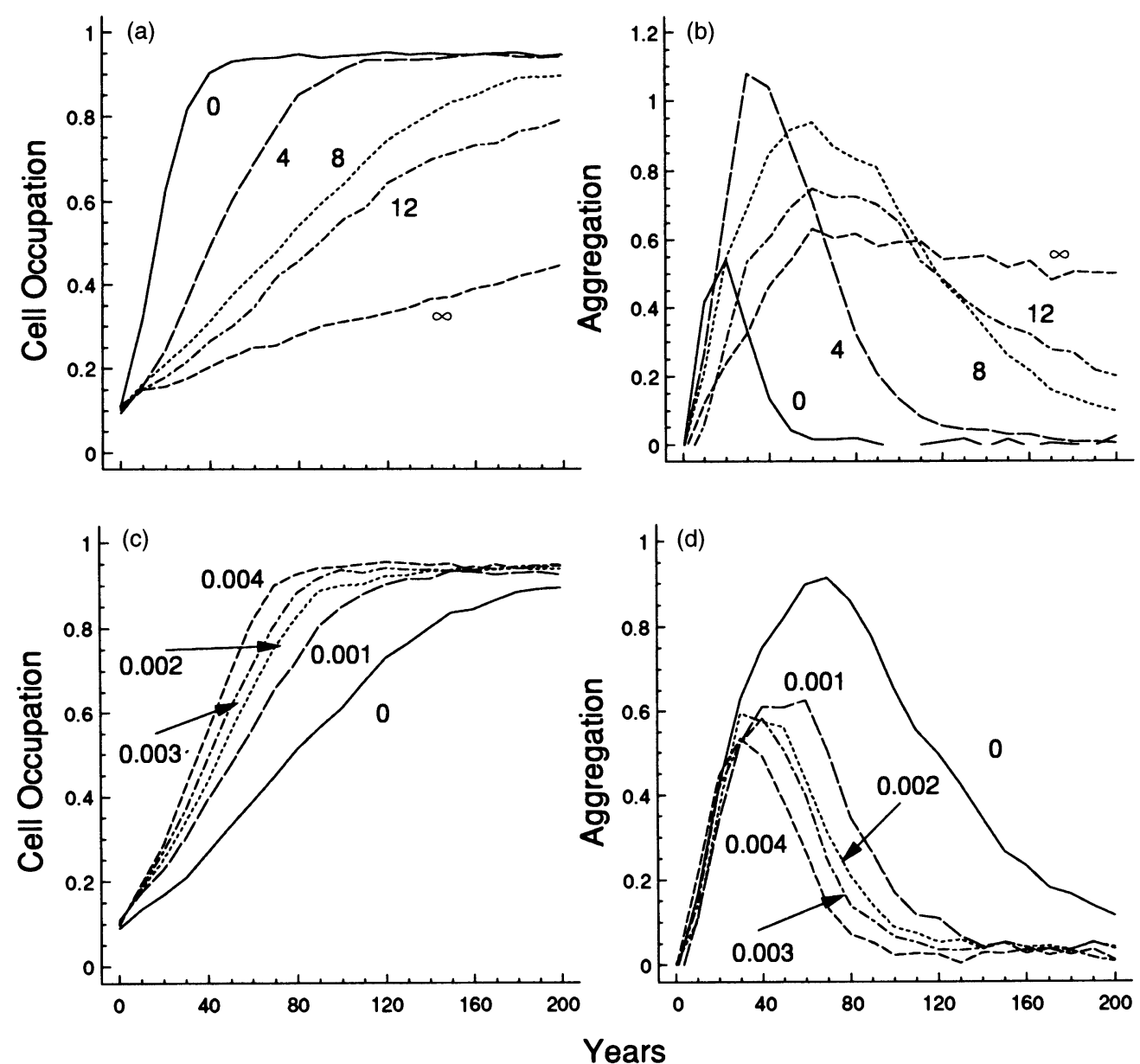

Fig. 5 Sensitivity of temporal changes in the fraction of cells occupied by mature trees $\left(N_{\mathrm{m}} / n^{2}\right)$ and the aggregation index $(\hat{C})$; (a) and (b) to changes in burn threshold $\left(B_{\mathrm{T}}\right)$, and (c) and (d) to changes in the fraction of seedlings dispersed $(\gamma)$. Initial $=0.1$ and trees are randomly distributed. Note that in caption (b), $\hat{C}$ drops slightly below zero for $B_{\mathrm{T}}=0$. See text for further explanations of parameters and indices.

tition. Further, as mature tree density increases so too does the probability that a dispersed seedling will find itself near fire-protecting trees. The net result is that even low levels of seed dispersal greatly enhance tree spread.

\section{FIRE MAINTAINS PATCHINESS}

In our model, fire maintains clumps of trees by preferentially burning those young plants which are isolated from the clumps. Protection of a seedling from annual fires requires that it be in the proximity of trees (i.e. seedling mortality is inversely density dependent) and that these trees be sufficiently large to have competitively displaced grass and thus reduced the fuel available to cause fire mortalities to seedlings.

A previous study by Green (1989) showed how fire, seed dispersal and the distributions of plants could profoundly affect population dynamics, spatial patterning and community structure. A major difference between our model and Green's is in the dynamics of fire. Green assumed that fires ignite at random locations in the habitat, with a Poisson distribution in frequency and negative exponential distribution in the area burnt. In his system each plant species has its own level of susceptibility to burning and post-fire time interval during which growth and reproduction begin to occur. Fire contributes to the patchiness of the system by burning the inferior competitor in areas where two competing species overlap. Our mechanism and that of Green are two different ways of promoting patchiness through the action of fire.

\section{MODEL PREDICTIONS}

The simple modelling framework developed here makes several testable predictions about tree population dynamics at Lamto.

First, although clumping is an inevitable consequence of our assumption that most tree recruitment occurs in cells adjacent to the mother tree, fire reinforces the clumped distribution of trees and the 'smoothness' of these clumps by selecting out isolated and semi-isolated seedlings. We therefore predict that, even when no seed dispersal occurs, higher maximum levels of the aggregation index $\hat{C}$ (eqn 6) should be attained in fire-treated plots than in fire-protected ones. 
Tree biology, fire and spatial population dynamics
Secondly, although it is not surprising that fire should slow down the rate of spread of some trees in humid savannahs, it is not obvious on what time scale this should occur. We predict that in the absence of seed dispersal, fire should increase the doubling time of savannah trees at Lamto from 6 years to at least 30 years, and that rather than taking c. 350 years to attain an equilibrium level of trees in a 0.25 -ha system, annual fires will prolong this to about 1200 years. A simple calculation indicates that, in the absence of dispersal, tree patches advance a $i$ an average rate of c. $1 \mathrm{~m}$ every 50 years. Of course, this latter prediction will be highly sensitive to the scale of the system, such as ours assuming at most one mature tree per square metre.

Thirdly, our finding that fire either has no effect on the equilibrium tree density or drives trees out of the system is a consequence of fire acting in an inversely density-dependent fashion over all tree densities. We predict that at Lamto, mortalities from fire should have no effect on the eventual equilibrium density of trees, and that at equilibrium approximately $90 \%$ of $1-\mathrm{m}^{2}$ patches should have a mature tree. Further, the model indicates that fire is most likely to have a halting effect on the spread of trees in systems with low density, regular tree distributions.

There is currently little data to test or corroborate these predictions. For instance, Dauget \& Menaut (1992) found a c. 30\% increase in tree density over a 20 -year period ( 5 annually burnt plots, each of 0.25 ha). Simulations of our model with an initially random distribution of trees predict a larger value of $44 \%$ (mean of 20 simulations). Possible reasons for this discrepancy based on the model include (i) an underestimation of mortalities due to fire, (ii) an overestimation of recruitment rate, and/or (iii) the non-inclusion of direct competitive effects. Until further experimental and modelling studies are conducted we cannot weigh the relative influences of these and other factors.

\section{Acknowledgements}

We thank Ian Noble for helpful discussion, and Mark Rees and two anonymous reviewers for comments on an earlier draft of this study.

\section{References}

Antonovics, J. \& Fowler, N.L. (1985) Analysis of frequency and density effects on growth in mixtures of Salvia splendens and Linum grandiflorum using hexagonal fan designs. Journal of Ecology, 73, 219-234.

Czaran, T. \& Bartha, S. (1992) Spatiotemporal dynamic models of plant populations and communities. Trends in Ecology and Evolution, 7, 38-42.
Dauget, J.M. \& Menaut, J.C. (1992) Evolution sur 20 ans d'une parcelle de savanne boisée non-protégée des feux dans le réserve de Lamto (Côte d'Ivoire). Candollea, 47, 621-630.

Eagleson, P.S. (1988) Stability of tree-grass vegetation systems. Climate-Vegetation Interactions (eds C. Rosenzweig and R. Dickinson), pp. 106-109. Proc. Workshop NASA/Goddard Space Flight Centre, Greenbelt.

Frost, P., Medina, E., Menaut, J.C., Solbrig, O., Swift, M. \& Walker, B. (1986) Responses of savannas to stress and disturbance. Biology International, Special Issue 10.

Frost, P.G. \& Robertson, F. (1987) The ecological effects of fire in savannas. Determinants of Tropical Savannas (ed. B. H. Walker), pp. 93-140. IRL Press, Oxford.

Gignoux, J. (1988) Modélisation de la Dynamique d'une Population Ligneuse. Application à l'Etude d'une Savane Africaine. DEA thesis, INAPG-University of Paris XI.

Gillon, D. (1983) The fire problem in tropical savannas. Tropical Savannas (ed. F. Bourlière), pp. 617-641. Elsevier, Amsterdam.

Green, D.G. (1989) Simulated effects of fire, dispersal and spatial pattern on competition within forest mosaics. $\mathrm{Veg}$ etatio, 82, 139-153.

Guiblin, P. (1992) Etude de la Repartition Spatiale du Peuplement Ligneux en Savane Arbustive de Côte d'Ivoire. DEA thesis, Université de Paris XI.

Menaut, J.C. (1977) Evolution of plot protected from fire since 13 years in a Guinea savanna of Ivory Coast. Actas del IV Symposium Internacional de Ecologia Tropical (Panama), 2, 541-558.

Menaut, J.C. (1983) The vegetation of African savanahs. Tropical Savannas (ed. F. Bourlière), pp. 109-149. Elsevier, Amsterdam.

Menaut, J.C. \& César, J. (1979) Structure and primary productivity of Lamto savannas, Ivory Coast. Ecology, 60, $1197-1210$

Menaut, J.C., Gignoux, J., Prado, C. \& Clobert, J. (1990) Tree community dynamics in a humid savanna of the Cote-D'Ivoire: modelling the effects of fire and competition with grass and neighbours. Journal of Biogeography, 17, 471-481.

Norton-Griffiths, M. (1979) The influence of grazing, browsing and fire on the vegetation dynamics of the Serengeti. Serengeti: Dynamics of an Ecosystem (eds A. R. E. Sinclair and M. Norton-Griffiths), pp. 310-352. University of Chicago Press, Chicago.

Pellew, R.A.P. (1983) The impact of elephant, giraffe and fire upon the Acacia tortilis woodlands of the Serengeti. African Journal of Ecology, 21, 41-74.

Prado, C. (1988) Un Modèle de Succession Végétale: Rôle des Traits Biologiques des Espèces et des Contraintes Spatiales. PhD thesis, Université de Paris VI.

Sanford, W.W., Obot, E.A. \& Wari, M. (1982) Savanna vegetational succession. Nigerian Savanna (eds W. W. Sanford, H. M. Yefusu and J. S. O. Ayeni), pp. 3-22. Kainji Lake Research Institute, New Bussa.

Schoener, T.W. (1983) Field experiments on interspecific competition. American Naturalist, 122, 240-285.

Trollope, W.S.W. (1984) Fire in savanna. Ecological Effects of Fire in South African Ecosystems (eds P. de V. Booysen and N. M. Tainton), pp. 149-176. Springer, Berlin.

Walker, B.H., Ludwig, D., Holling, C.S. \& Peterman, R.M. (1981) Stability of semi-arid savanna grazing systems. Journal of Ecology, 69, 473-498.

Received 5 May 1993

Revised version accepted 3 September 1993 